\title{
Evaluation Of Anxiety During Nasal Pack Removal In Patients Operated Under Local Versus General Anesthesia
}

Amer Sabih Hydri, Muhammad Junaid Alam, Iqbal Hussain Udaipurwala, Furqan Mirza

\section{ABSTRACT}

Objective: To evaluate the anxiety experienced before, during and after conventional paraffin gauze nasal pack removal in patients operated under local versus general anesthesia.

Study design: Comparative study.

Place and duration of study: Department of ENT, Combined Military Hospital Sialkot and PAF Hospital Shorkot from July 2017 to June 2018.

Material and methods: A total of 120 patients planned for Septoplasty were enrolled and divided into two groups. Sixty patients were to be operated under local anesthesia (Group A) while the other 60 were undergoing the same procedure under general anesthesia (Group B). Conventional paraffin gauze nasal packing was done for 24 hours in all 120 patients. Hamilton Anxiety Rating Scale (HAM-A) was used to determine the patients' anxiety in both groups, 1 hour pre-operatively, immediately before and 1 hour after nasal pack removal.

Results: The mean Hamilton Anxiety Scale assessment scores in both groups were of 'mild' category. The highest scores in both groups were observed immediately before nasal pack removal, with a range of 15-18, while the lowest scores in both groups were documented one hour after pack removal with a range of 13-16. Anxiety level in patients operated under general anesthesia was slightly lower than patients administered local anesthesia mean score of $16.40 \pm 0.763$ vs $17.21 \pm$ $0.666(\mathrm{p}<0.001)$.

Conclusion: Anxiety during nasal pack removal is mainly associated with prior pain experienced during nasal pack insertion. It is recommended that proper analgesia, adequate topical anesthesia, gentle insertion would make this process less distressing and will subsequently result in less anxiety at its removal.

Keywords: Anxiety, Nasal Surgery, Nasal Packing, Septoplasty, Post-Operative Care

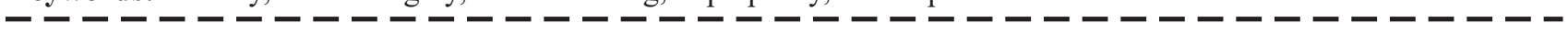

\section{INTRODUCTION:}

The earliest recorded reference to the use of nasal packing is found in the writings of Hippocrates in controlling epistaxis ${ }^{1}$. Nasal packing is commonly used to control bleeding following nasal surgery like septoplasty, turbinoplasty and functional endoscopic sinus surgery (FESS). An ideal nasal pack should cause minimal discomfort at insertion, exhibit a good splinting effect, control bleeding, and have minimal complications ${ }^{2}$. Nasal packing has some inherent disadvantages, such as causing discomfort, pain, nasal mucosal damage, septal perforation, allergic reaction, sleep/respiratory disturbances and decreased arterial oxygen

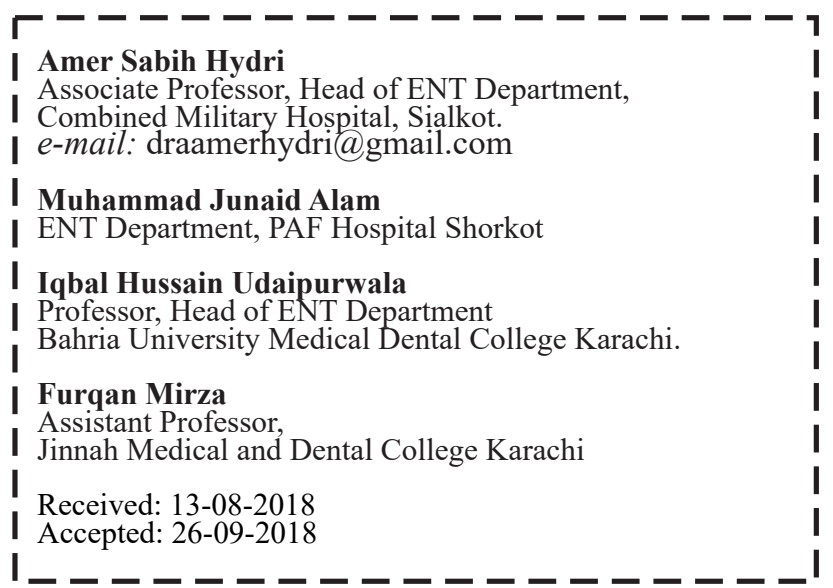

saturation during sleep. Traumatic insertion of nasal packs can also result in iatrogenic bleeding ${ }^{3}$. Attempts have been made to produce materials that will address these problems, including removable and absorbable packing, and a multitude of nasal packing materials has emerged in recent years ${ }^{4}$. It is estimated that $60-80 \%$ of surgical patients experience substantial anxiety prior to surgery. Apart from pathophysiological responses such as hypertension and dysrhythmias, anxiety may also worsen the patients' perception of pain and may impede overall perioperative satisfaction ${ }^{5}$. Anxiety is a feeling of apprehension and fear, characterized by physical symptoms such as palpitations, sweating, and feelings of stress. Patient's anxiety can be measured objectively using various tests e.g., Hamilton Anxiety Rating Scale (HAM-A), State-Trait Anxiety Inventory Clinical Assessment Scale (STAI-S) and Hospital Anxiety Depression Scale (HADS). We used Hamilton Anxiety Scale (HAMA) in our study.

It is our experience that those patients who had their nasal packing performed under Local anesthesia, having experienced the discomfort at insertion, have more anxiety because of the distressing memory, prior to their removal. On the other hand, patients who were operated under general anesthesia, being unaware of the discomfort at the time of nasal packing exhibit lesser anxiety prior to removal of the nasal packs. Search of the internet revealed a paucity of 
published literature on anxiety due to nasal packs, and none on this topic. This study was thus formulated to scientifically document and evaluate the anxiety experienced before, during and after conventional paraffin gauze nasal pack removal, using Hamilton Anxiety Scale, in patients operated under local versus general anesthesia.

\section{PATIENTS AND METHODS:}

A total of 120 adult patients of either gender, reporting to the ENT departments of Military Hospital Sialkot and Shorkot, planned for elective Septoplasty operation, were enrolled for this comparative study and divided into two groups. Sixty patients were to be operated under local anesthesia (Group A) while the other 60 were undergoing the same procedure under general anesthesia (Group B). Written consent was taken from the patients and approval of a protocol for this study was obtained from the local ethical committee. Exclusion criteria included any psychological disorder and conditions requiring other nasal surgery with septoplasty like turbinectomy/turbinoplasty. None of the patients was pre-medicated on the night prior to surgery. All patients were evaluated and reviewed by a Psychologist. The educational qualification of all patients was documented and classified as illiterate, primary school, middle, Matric and graduates. Each patient was handed over a chart containing information about what to expect in the post-operative period. All surgeries were performed by senior otolaryngologists, using the same standard operative technique. At the end of surgery, anterior nasal packing was done using conventional paraffin gauze packs and left in place for 24 hours.

Before removing the nasal packs 4\% Xylocaine solution was instilled around the nasal packs for 20 minutes to facilitate their relatively painless removal. Hamilton Anxiety Rating Scale (HAM-A) was used to measure the patients' anxiety in both groups A \& B, 1 hour pre-operatively ; immediately before nasal pack removal and 1 hour after removal of nasal pack. (Figure 1). The results were analysed using the student's paired t-test. A 'p value' of $<0.001$ was considered statistically significant.

\section{RESULTS:}

The age of 120 patients enrolled for this study ranged from 18 to 44 years with a mean of 26.3 years. The age range of 60 patients in group A was 18 to 40 years (Mean age: 25.4 years), while that of group B was 18 to 44 years (Mean age: 27.1 years). There was a total of 74 male and 46 female patients in this study (fig 2). In group A there were 38 males and 22 females (ratio of 1.72:1) while in group B there were 36 males and 24 female patients (ratio of 1.5:1). Regarding the education status of the patients, majority were primary school graduates $(35 \% . \mathrm{n}=42)$, followed by high school graduates (26.66\%. $\mathrm{n}=32)$ (fig. 3 ).

The mean Hamilton Anxiety Scale assessment scores in both groups were of 'mild' category. The most common symptoms $(54 \%)$ reported by patients were Somatic (muscular) and Respiratory symptoms. The highest scores in both groups were observed immediately before nasal pack removal, with a range of 15-18, while the lowest scores in both groups were documented one hour after pack removal with a range of 13-16. (table 1). Surprisingly the anxiety prior to nasal pack removal was even higher than anxiety before surgery (table 1). There was statistically significant difference among both groups recorded immediately before the nasal pack removal. Anxiety level in group B (Patients administered general anesthesia) was lower than group A (Patients administered local anesthesia) $(\mathrm{p}<0.0001)$.

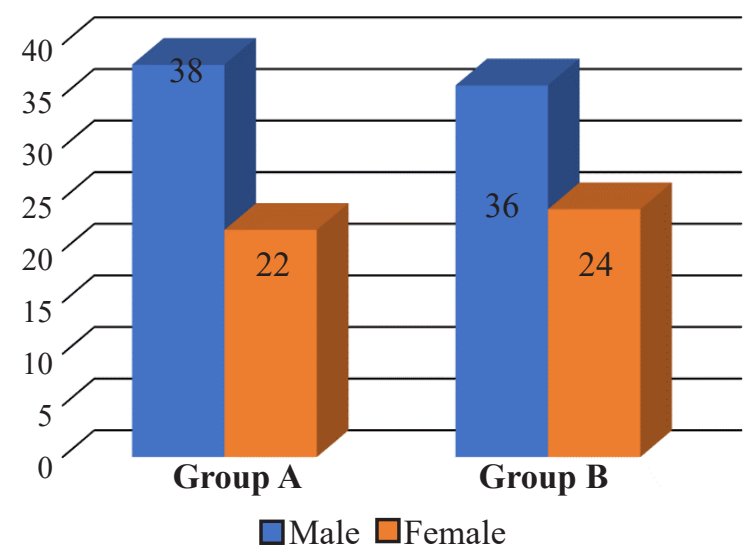

Fig. 2. Gender distribution in both groups A and B

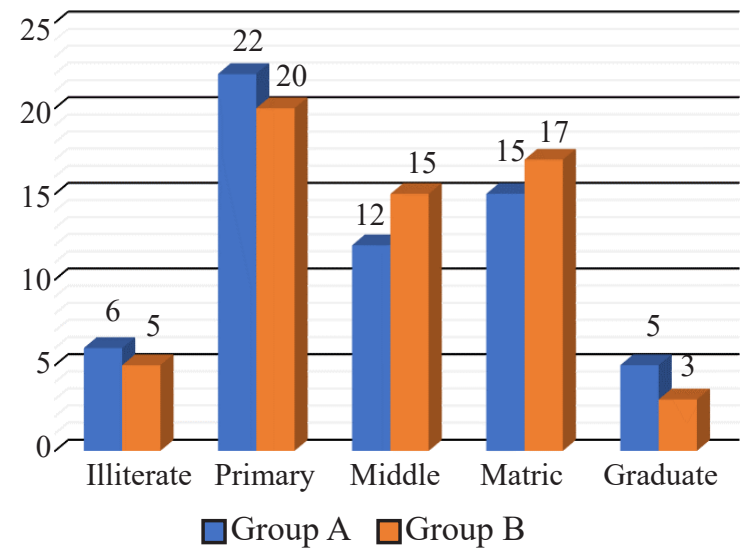

Fig 3. Educational status of patients in both groups A and B

\section{DISCUSSION:}

Septoplasty is one of the most commonly performed procedures for the treatment of deviated nasal septum ${ }^{6,7,8}$. Septal surgery may lead to many complications and to prevent these complications, nose is routinely packed after surgery ${ }^{9,10,11}$. Nasal packing is related with numerous drawbacks like uneasiness to the patient during packing and at the time of removal. In addition, it may cause headache, sinusitis, reduced sleep quality, respiratory difficulties, decreased oxygen saturation and toxic shock syndrome ${ }^{12,13}$. Our study is the first one to document and compare the 
Amer Sabih Hydri, Muhammad Junaid Alam, Iqbal Hussain Udaipurwala, Furqan Mirza

\section{Hamilton Anxiety Rating Scale (HAM-A)}

Classification of symptoms: 0-absent; 1-mild; 2-moderate; 3-Severe; 4-Incapacitating.

HAM-A score level of anxiety: $<17$ mild; $18-24$ mild to moderate; $25-30$ moderate to severe

Symptoms

Date:

1. Anxious mood

01234

- Worries

- Anticipates worst

2. Tension 01234

- Startles

- Cries easily

- Restless

- Trembling

3. Fears 01234

- Fear of the dark

- Fear of strangers

- Fear of being alone

- Fear of animal

4. Insomnia

- Difficulty falling asleep or staying asleep

- Difficulty with nightmares

5. Intellectual

- Poor concentration

- Memory impairment

6. Depressed Mood

- Decreased interest in activities

- Anhedonia

- Insomnia

7. Somatic complaints - Muscular

- Muscle aches or pains

- Bruxism

8. Somatic complaints - Muscular

- Tinnitus

- Blurred vision
9. Cardiovascular Symptoms

- Tachycardia

- Palpitation

- Chest pain

- Sensory of feeling faint

10. Respiratory Symptoms

- Chest pressure

- Choking sensation

- Shortness of breath

11. Gastrointestinal Symptoms

- Dysphagia

- Nausea of vomiting

- Constipation

- Weight loss

12. Genitourinary Symptoms

- Urinary frequency or urgency

- Dysmenorrhea

- Impotence

13. Autonomic Symptoms

- Dry mouth

- Flashing

- Pallor

- Sweating

14. Behavior at Interview

- Fidgets

- Tremor

- Paces

Fig. 1. Hamilton Anxiety Rating Scale

\begin{tabular}{|l|c|c|c|c|c|c|c|c|c|}
\hline & \multicolumn{3}{|c|}{ 1hour pre-operatively } & \multicolumn{3}{c|}{$\begin{array}{r}\text { Immediately before pack } \\
\text { removal }\end{array}$} & \multicolumn{3}{c|}{ 1 hour after pack removal } \\
\hline & Range & Mean & St. deviation & Range & Mean & St. deviation & Range & Mean & St. deviation \\
\hline Group A & $14-16$ & 15.30 & 0.720 & $15-18$ & 17.21 & 0.666 & $13-16$ & 14.40 & 0.994 \\
\hline Group B & $14-16$ & 15.35 & 0.732 & $15-18$ & 16.40 & 0.763 & $13-16$ & 14.26 & 0.936 \\
\hline
\end{tabular}

Table 1 Hamilton Anxiety Rating Scale Scores in Both Groups A and B

anxiety experienced prior to conventional paraffin gauze nasal pack removal in patients operated under local versus general anesthesia.

We performed septoplasty in this study and the pack was removed after 24 hours in all the patients. Hamilton Anxiety Rating Scale (HAM-A) was used for recording anxiety level. It was introduced by Max Hamilton in 1959 to measure both psychic and somatic anxiety levels in patients objectively. The score consists of 14 items, each defined by a series of symptoms. Each item is scored on a scale of 0 to 4 (not present, mild, moderate, severe and incapacitating), with a total score range of 0 to 56 . A score of 17 or less indicates mild anxiety, 18 to 24 indicates mild to moderate anxiety while a score of 25 to 30 indicates moderate to severe anxiety.

Sahin in his study concluded that State/Trait Anxiety Inventory, (STAI) anxiety levels did not decrease significantly after operation, but only after removal of nasal packs ${ }^{14}$. This is commensurate with our findings where the Hamilton 
anxiety index score before pack removal was even higher than before surgery. A study by Hosemaan about anxiety levels in patients undergoing endoscopic sinus surgery observed that patients with information about the surgery and especially female patients had a significantly higher level of pre-operative anxiety ${ }^{15}$. Rozanska-Kudelska in his study showed no significant difference in patient anxiety before and after endoscopic sinus surgery and septum surgery ${ }^{16}$ while Muluk claims anxiety levels of patients having endoscopic sinus surgery decreased after the operation ${ }^{17}$. Education of the patient may alter the perception of pain and anxiety. Increased awareness about the procedure and peri-operative period may either lessen or sometime increase the anxiety of the individual. There are studies revealing education level may enhance anxiety ${ }^{18}$.

Sahin noted a statistically significant increase in patients' anxiety before pack removal ${ }^{14}$ which is fairly similar and commensurate with our findings. In another study designed to alleviate patients' anxiety, Sahin and Aras ${ }^{19}$ used lidocaine infiltration into nasal packing 15 minutes prior to removal but their study showed a higher Hospital Anxiety and depression score (HADS), even in the saline group. In one study Dutta et $\mathrm{al}^{20}$ evaluated pain while nasal packing, where pain was moderate in locally anesthetized nasal cavities compared to severe pain in those case where no local anesthesia was used. This corroborates our hypothesis that patients who have had nasal packing done under local anesthesia will be potentially more apprehensive regarding pack removal pain or discomfort. A study by Hosemaan revealed that the preoperative anxiety of the patient also increased on the information received from friends/ relatives or other patients. In contrast another study by Muluk using HADS claims that a patient well-informed about the nasal packing and hospital conditions will not exhibit exaggerated anxiety or depression. This substantiates our findings, as all patients were handed over charts containing information about what to expect in the post-operative period and most if not, all exhibited variable mild anxiety.

The period of nasal packing after nasal surgery is also a crucial factor for pain and anxiety in the patients ${ }^{21}$. There is no absolute consensus about the duration of nasal packing, however most ENT surgeons leave it for at least 24 to 48 hours ${ }^{22}$, but now numerous surgeons favour nasal packing only for 24 hours $^{23}$. In our study we removed the pack after 24 hours in all patients and re-packing because of bleeding was not required in any case. Removal of nasal pack is described by many patients as the most painful and excruciating experience of their life ${ }^{24}$. To reduce this problem many absorbable materials have been tried by surgeons, but apprehensions have been stated regarding bio-compatibility and cost effectiveness ${ }^{25}$.

\section{CONCLUSION:}

Patients who remembered their nasal packing being performed under local anesthesia exhibited more anxiety before nasal pack removal compared to those who had nasal packing done under general anesthesia. It is recommended that proper analgesia, adequate topical anesthesia, gentle insertion would make this process less distressing and subsequently result in reduced anxiety at their removal.

\section{Conflict of interest:}

The authors claim no conflict of interest or any financial funding

\section{REFERENCES:}

1. Lascaratos JG, Constantinos C. Trompoukis CC, John V. Segas JV and Assimakopoulos DA. From the Roots of Rhinology: The Reconstruction of Nasal Injuries by Hippocrates. Annals Otol Rhinol Laryngol 2003; 112(2):15962.

2. Farooq M. Ventilating anterior nasal packing after Septoplasty. Int J Path.2016:14(1). http://jpathology.com/wpcontent/uploads/2016/06/Ventilating-Anterior-Nasal-Packingafter-Septoplasty1.pdf

3. Traboulsi H, Alam E, Hadi U. Changing trends in the management of Epistaxis. Int J Otolaryngol. 2015; article ID 263987. Published online 2015. Doi: 10.1155/2015/ 263987.

4. Wang J, Cai C, Wang S (2014) Merocel versus Nasopore for Nasal Packing: A Meta-Analysis of Randomized Controlled Trials. PLoS ONE 9(4): e93959. doi:10.1371/journal. pone.0093959.

5. Jlala HA, French JL, Foxall GL, Hardman JG, Bedforth NM. Effect of preoperative multimedia information on perioperative anxiety in patients undergoing procedures under regional anaesthesia. Br J Anaesth., 2010; 104 (3): 369-74.

6. Rashid A, Aziz B, Khan MA, Hameed A. Analytical assessment of nasal packing in septoplasty. Pak J Med Health Sci 2011; 5(2): 232-5.

7. Sahin C, Aras HI. The effect of nasal packing removal on patient's anxiety. Med. Arh. 2015; 69(9): 393-5. Doi: 10.5455/medarh. 2015;69:393-395

8. Daudia A, Alkhaddour U, Sithole J, Mortimore S, A prospective objective study of the cosmetic sequelae of nasal septum surgery. Acta Otolaryngol 2006; 126: 1201-5.

9. Bashir S, Jawaid A, Nawaz FH. Randamized controlled trial between 24 and 48 hours nasal packing after sub mucosal resection. Journal of Rawalpindi Medical College 2013; 17(1): $62-4$.

10. Muhammad IA, Nabil-ur-Rehman. Complications of the surgery for deviated nasal septum. J Coll Physicians Surg Pak 2003; 13: 7-12.

11. Lachanas VA, Karatzias GT, Pinakas VG, Hatzuoannou JK. The use of tetracaine $0.25 \%$ solution in nasal packing removal. Am J Rhinol 2006; 20: 483-5.

12. Ansari MA, Islam U, Hirani I, Khayani IAM, Kashmiri ZA. Trans-septal suturing technique without intra-nasal packing in nasal septal surgery Pak J Surg 2013; 29(2): 123-6.

13. Udaipurwala IH, Ahmed S, Hussain J. Comparison of Finger Glove and Ribbon Gauze Nasal Packing after Septal Surgery. Journal of Bahria University Medical \& Dental College. 2016; 6(3): 156-159.

14. Sahin C, Aras HI. Influence of nasal pack removal on patients' anxiety after Septoplasty. Turk J ENT 2015;25(5):266-70. 
Amer Sabih Hydri, Muhammad Junaid Alam, Iqbal Hussain Udaipurwala, Furqan Mirza

15. Hosemann W, Loew TH, Forster M, Kühnel T, Beule AG. Perioperative pain and anxiety in endoscopic sinus surgery. Laryngorhinootologie 2011; 90:476-80.

16. Rózañska-Kudelska M, Szulc A, Matulka M, Simonienko K, Rogowski M. Quality of life, depression and anxiety symptoms in patients with chronic rhinosinusitis with polyps treated by endoscopic sinus surgery. Pol Merkur Lekarski 2012; 32: 228-31.

17. Muluk NB, Oðuztürk O, Ekici A, Koç C. Emotional effects of nasal packing measured by the Hospital Anxiety and Depression Scale in patients following nasal surgery. J Otolaryngol 2005; 34: 172-7.

18. Coplan JD, Hodulik S, Mathew SJ, Mao X, Hof PR, Gorman $\mathrm{JM}$ et al. The relationship between intelligence and anxiety: an association with subcortical white matter metabolism. Front Evol Neurosci.1 Feb 12/https://doi.org/10.3389 /fnevo.2011.00008.

19. Sahin C, Aras HI. Effect on patient anxiety of lidocaine infiltration into nasal packing after septoplasty: prospective, controlled study. J Laryngol Otol. 2015; 129(8): 784-7.
20. Dutta S, Mukherjee A, Saha J, Biswas G, Haldar D, Sen I, Sinha R. Modified Technique of Anterior Nasal Packing: A Comparative Study Report.Indian J Otolaryngol Head Neck Surg. 2012; 64(4): 341-45.

21. Yilmazer C, Sener M, Yilmaz I, Erkan AN, Cagisi CA, Donmez A. Pre-emptive analgesia for removal of packing: A double blind placebo-controlled study. AurisNasus Larynx2007; 34(4): 471-5.

22. Faistauer M, Faistauer Â, Grossi RS, Roithmann R. Clinical outcome of patients with epistaxis treated with nasal packing after hospital discharge. Braz J Otorhinolaryngol. 2009: 75(6): 857-865.

23. Jinnas K, Bizako A, Fragiadakis G, Bourialas C. Optimal time for removal of nasal packing after septoplasty. A comparative study. Rhinology 2007; 45: 68-71.

24. Gencer ZK, Ozkiris M, Gencer M, Saydam L. Comparison of ropivacaine, bupivacaine, prilocaine and lidocaine in the management of pain and haemorrhage during nasal packing removal. Am J Rhinol Allergy 2013; 27: 423-5.

25. Acioglu E, Edizer DT, Yigit O, Onur F, Alkan Z. Nasal septal packing: which one?. Eur Arch Otorhinolaryngol 2012; 269: 1777-81. 